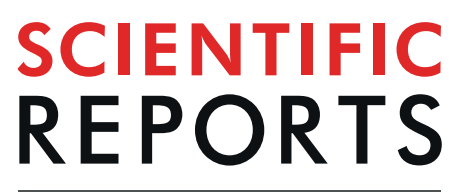

natureresearch

Check for updates

\title{
Type 2 diabetes impacts colorectal adenoma detection in screening colonoscopy
}

Lorenzo F. Ottaviano ${ }^{1}$, Xueying Li ${ }^{2}$, Matthew Murray ${ }^{1}$, Jesse T. Frye ${ }^{1}$, Brandon E. Lung ${ }^{1}$, Ying Yi Zhang ${ }^{1}$, Jie Yang ${ }^{2}$, Erin M. Taub ${ }^{1}$, Juan Carlos Bucobo ${ }^{1}$, Jonathan M. Buscaglia ${ }^{1}$, Ellen $\mathrm{Li}^{1}$ \& Joshua D. Miller ${ }^{1 \mathrm{\varpi}}$

Background: Diabetes is associated with an increased risk of colorectal cancer (CRC). We conducted a retrospective analysis of adenoma detection rates (ADR) in initial screening colonoscopies to further investigate the role of diabetes in adenoma detection. Methods: A chart review was performed on initial average risk screening colonoscopies (ages 45-75) during 2012-2015. Data collected included basic demographics, insurance, BMI, family history of CRC, smoking, diabetes, and aspirin use. Multivariable generalized linear mixed models for binary outcomes were used to examine the relationship between diabetes and variables associated with CRC risk and ADR. Results: Of 2865 screening colonoscopies, 282 were performed on patients with type 2 diabetes (T2DM). Multivariable analysis suggested that T2DM $(\mathrm{OR}=1.49,95 \% \mathrm{Cl}: 1.13-1.97, \mathrm{p}=0.0047)$ was associated with an increased $\mathrm{ADR}$, as well as smoking, older age, higher BMI and male sex (all $\mathrm{p}<0.05$ ). For patients with T2DM, those not taking diabetes medications were more likely to have an adenoma than those taking medication $(\mathrm{OR}=2.38,95 \%$ $\mathrm{Cl}: 1.09-5.2, \mathrm{p}=0.03)$. Conclusion: T2DM has an effect on ADR after controlling for multiple confounding variables. Early interventions for prevention of T2DM and prescribing anti-diabetes medications may reduce development of colonic adenomas and may contribute to CRC prevention.

Colorectal Cancer (CRC) is the fourth most common cancer in the United States (US) and second most lethal ${ }^{1}$. Most colon cancers develop via a multistep process involving a series of somatic genetic mutations and histopathologic changes that accumulate over time that is estimated to take approximately $10-15$ years ${ }^{2}$. Optical colonoscopy screening has been considered the gold standard for CRC screening, because of its ability to view the entire colon and to both detect and remove polyps during the same procedure, which have been demonstrated to reduce the subsequent risk of $\mathrm{CRC}^{3}$. However, despite the effectiveness of CRC screening it is estimated 50,680 people in the US will die in 2018 from CRC $^{4}$.

Identifying and understanding risk factors and conditions that increase the risk of CRC is essential to optimizing the effectiveness of CRC screening. There are many established risk factors for CRC: age, race, male sex, family history in a first degree relative, smoking, and $\mathrm{BMI}^{5,6}$. Studies have also shown that individuals with diabetes mellitus have an increased risk of developing CRC when compared to patients without the disease ${ }^{7}$. This is important as diabetes mellitus is estimated to affect $9.4 \%$ of the population, or approximately 30.3 million people in the US, with type 2 diabetes accounting for 90 to $95 \%$ of diabetes cases ${ }^{8}$. To address the question as to how diabetes mellitus increases the risk of CRC, studies have been conducted to address whether the association with the disease also exists for precursor stages along the adenoma-carcinoma progression pathway, by examining the association between diabetes mellitus and adenoma detection rate (ADR) (detection of $\geq 1$ adenoma). While the results have been mixed ${ }^{9-13}$, particularly one study conducted in Black/African American women ${ }^{9}$, a recent meta-analysis indicated that diabetes mellitus is associated with an increased ADR and increased advanced adenoma detection rate $(\mathrm{AADR})^{10}$. One of the drawbacks of the meta-analysis is that potential confounding variables were included to varying degrees in the studies analyzed. A more recent study examining a random selection of 1800 colonoscopies in a single cohort, did not detect a significant effect of diabetes mellitus when controlled for confounding variables ${ }^{12}$.

${ }^{1}$ Department of Medicine, Renaissance School of Medicine at Stony Brook University, Stony Brook, New York, United States of America. ${ }^{2}$ Department of Family, Population and Preventive Health, Renaissance School of Medicine at Stony Brook University, Stony Brook, New York, United States of America. ${ }^{凶}$-mail: Joshua.Miller@ stonybrookmedicine.edu 
To further examine the role of type 2 diabetes in colorectal adenoma-carcinoma progression, we conducted a retrospective analysis of all initial screening colonoscopies performed at a single institution, while attempting to control for confounding variables, including those previously associated with increased risk of CRC. In addition, we analyzed the effect of anti-diabetes medication and glycemic control as measured by fasting plasma glucose (FPG) (measured on the day of the procedure) and hemoglobin A1c (HbAlc) (measured within twelve months of the procedure). We report the results of this analysis, which confirms that type 2 diabetes is associated with increased ADR while controlling for confounding variables, including BMI.

\section{Methods \\ Collection of clinical data from initial screening colonoscopies performed in 2012-2015. This} retrospective cohort study was approved by the Stony Brook University Institutional Review Board (IRB \# 180023) and all methods were performed in accordance with the guidelines and regulations of Stony Brook University IRB. A wavier of consent was obtained by Stony Brook University IRB for retrospective collection and analysis for deidentified demographic and medical data. Patients who underwent screening colonoscopies at Stony Brook University Hospital from January 1, 2012 to December 31, 2015, were identified using endoscopy reporting software. Patients age $<45 \mathrm{y}$ or $>75 \mathrm{y}$, a history of previous colonoscopy, a history of inflammatory bowel diseases, known hereditary colorectal syndromes, detection of microscopic or macroscopic blood in stool and other alarm syndromes, detection of colonic masses or polyps on previous studies, were excluded from this analysis. Colonoscopies that were incomplete (did not reach the cecum) and those associated with poor bowel preparation were also excluded. Clinical metadata was manually collected on each patient using the electronic medical record (EMR) as documented at the time of screening colonoscopy and included: (1) age at time of initial screening colonoscopy (year); (2) sex (Male, Female); (3) race (White/European Ancestry, Black/African-Ancestry, Asian, Other); (4) Ethnicity (Non-Hispanic, Hispanic); (5) Insurance (Commercial, Medicare, Medicaid, Self-pay); (6) BMI (kg/m²); (7) Tobacco Exposure (Current within one year, Past greater than one year, Never); (8) Family history of CRC in a $1^{\text {st }}$ degree family member (Yes, No); (9) Documented diagnosis of diabetes (Yes, No).

For patients with diabetes mellitus, further data was collected using the EMR as documented at the time of screening colonoscopy and included: (1) FPG on day of screening colonoscopy; (2) HbA1c within 12 months of the procedure; (3) Insulin use (Yes, No); (4) Metformin use (Yes, No); (5) Sulfonylurea use (Yes, No) (6) Thiazolidinedione use (Yes, No); (7) Meglitinide use (Yes, No); (8) GLP-1 Agonist use (Yes, No); (9) DPP-4 inhibitor use (Yes, No); and (10) SGLT-2 inhibitor use (Yes, No); (11) Acarbose use (Yes, No).

The colonoscopy report was reviewed to determine if a colonic biopsy or polypectomy was performed and number of polyps detected. If a biopsy or polypectomy was performed the pathology report was reviewed to collect data on polyp type (hyperplastic vs. adenomatous). If an adenomatous polyp was removed further descriptive data was collected to characterize size and location (right colon vs. left colon). We defined a right colonic adenoma as arising from cecum, ascending colon, hepatic flexure, or transverse colon and left colonic adenoma as arising from splenic flexure, descending colon, sigmoid colon, rectosigmoid, or rectum. For each adenomatous polyp we collected data on polyp histology (tubular, tubulovillous, villous), presence of dysplasia (low grade, high grade), and adeno-carcinoma (yes or no). We defined an advanced adenoma as any adenomatous polyp containing at least one of the following features: villous or tubulovillous histology, high grade dysplasia, or size $\geq 1 \mathrm{~cm}$. We defined a high risk adenoma as any adenomatous polyp containing at least one of the following features: villous or tubulovillous histology, high grade dysplasia, size $\geq 1 \mathrm{~cm}$, or presence of $\geq 3$ adenomatous polyps.

Statistical analysis. Statistical analysis was performed utilizing the Biostatistics and Bioinformatics Share Resource at the Stony Brook University Cancer Center. Demographics were compared between diabetes and non-diabetes patients using either Wilcoxon rank sum test for continuous variables, and chi-square test with exact p-values from Monte-Carlo simulations for categorical variables. Univariate generalized linear mixed models (GLMM) were used to examine the marginal association between two clinical outcomes, adenoma detection and advanced adenoma detection, and patients' characteristics (diabetes diagnosis, smoking, family history of first degree relative, age, gender, race, ethnicity, BMI, insurance, trainee involvement) for the entire patient population (except 8 patients with type 1 diabetes), between two clinical outcomes and patients' characteristics (smoking, family history of first degree relative, age, gender, race, ethnicity, BMI, insurance, fellow involvement, $\mathrm{HbA1c}$, glucose, and anti-diabetic medication use) for patients with type 2 diabetes. Since patients that were treated by the same physician were natural clusters, physician was considered as random effect. Multivariable GLMM with physician as random effect was used to examine the relationship between potential risk factors and adenoma detection and advance adenoma detection for the entire patient population (except 8 patients with type 1 diabetes). For adenoma detection and advanced adenoma detection in subgroup analysis for patients with type 2 diabetes, only the factors that were significant based on univariate GLMMs were further considered in the multivariable GLMMs with physician as random effect. In each multivariable regression analysis, an OR $>1$ indicates that one category has more risk of having adenoma detection than the reference category, and OR $<1$ indicates that one category has less risk of having adenoma detection than the reference category ${ }^{14}$. A logistic regression model was used to examine the relationship between FPG and glycemic control based on HbA1c level among patients with type 2 diabetes who had both glucose and $\mathrm{HbAlc}$ results. ROC analysis was used to examine how well pre-procedure FPG predicts glycemic control. Statistical analysis was performed using SAS 9.4 and significance level was set at 0.05 (SAS Institute Inc., Cary, NC). All authors had access to the study data and have reviewed and approved the final manuscript. 


\begin{tabular}{|c|c|c|c|}
\hline & Diabetesn $=289$ & Non-diabetesn $=2576$ & P-value \\
\hline Age $(y)$ median \pm IQR & $57.4 \pm 10.0$ & $54.1 \pm 8.7$ & $<0.0001$ \\
\hline Male sex (\%) & $159(55.0 \%)$ & $1151(44.7 \%)$ & 0.0001 \\
\hline Race (\%) & & & $<0.0001$ \\
\hline White/European Ancestry (EA) & $223(77.2 \%)$ & $2271(88.2 \%)$ & \\
\hline Black/African Ancestry (AA) & $29(10.0 \%)$ & $140(5.4 \%)$ & \\
\hline Asian & $16(5.5 \%)$ & $72(2.8 \%)$ & \\
\hline Other & $21(7.3 \%)$ & $93(3.6 \%)$ & \\
\hline Hispanic ethnicity (\%) & $24(8.3 \%)$ & $197(7.6 \%)$ & 0.74 \\
\hline Family history of CRC & $11(3.8 \%)$ & $142(5.5 \%)$ & 0.27 \\
\hline Median BMI $\left(\mathrm{kg} / \mathrm{m}^{2}\right) \pm \mathrm{IQR}$ & $31.2 \pm 9.1$ & $27.3 \pm 6.6$ & $<0.0001$ \\
\hline Smoking (\%) & & & 0.0015 \\
\hline Current (within a year) & $43(14.9 \%)$ & $333(12.9 \%)$ & \\
\hline Quit (at least a year) & $105(36.3 \%)$ & $710(27.6 \%)$ & \\
\hline Never & $141(48.8 \%)$ & $1533(59.5 \%)$ & \\
\hline Aspirin use $(\%)^{3}$ & $87(30.1 \%)$ & $273(10.6 \%)$ & $<0.0001$ \\
\hline Fellow involvement (\%) & $50(17.3 \%)$ & $476(18.5 \%)$ & 0.63 \\
\hline Quality of colonoscopic prep & & & 0.0002 \\
\hline Excellent & $47(16.3 \%)$ & $604(23.4 \%)$ & \\
\hline Good & $198(68.5 \%)$ & $1730(67.2 \%)$ & \\
\hline Fair & $26(9.0 \%)$ & $108(4.2 \%)$ & \\
\hline Undocumented & $18(6.2 \%)$ & $134(5.2 \%)$ & \\
\hline Insurance (\%) & & & $<0.0001$ \\
\hline Commercial & $167(57.8 \%)$ & $1857(72.1 \%)$ & \\
\hline Medicare & $42(14.5 \%)$ & $244(9.5 \%)$ & \\
\hline Medicaid & $71(24.6 \%)$ & $423(16.4 \%)$ & \\
\hline Self-pay & $9(3.1 \%)$ & $52(2.0 \%)$ & \\
\hline \multicolumn{4}{|l|}{ Diabetes Type } \\
\hline Type I & $7(2.4 \%)$ & & \\
\hline Type 2 & $282(97.6 \%)$ & & \\
\hline Median FPG $(\mathrm{mg} / \mathrm{dl}) \pm \mathrm{IQR}^{1}$ & $129 \pm 51$ & & \\
\hline Median $\mathrm{HbAlc} \% \pm \mathrm{IQR}^{2}$ & $\begin{array}{l}7.2 \pm 1.5 \\
(55 \mathrm{mmol} / \mathrm{mol})\end{array}$ & & \\
\hline \multicolumn{4}{|l|}{ Anti-diabetes medications (\%) } \\
\hline None & $30(10.4 \%)$ & & \\
\hline Insulin & $59(20.4 \%)$ & & \\
\hline Metformin & $190(65.7 \%)$ & & \\
\hline Sulfonylurea & $73(25.3 \%)$ & & \\
\hline DPP4 inhibitors & $38(13.1 \%)$ & & \\
\hline Thiazolidinedione & $10(3.5 \%)$ & & \\
\hline GLP1 agonists & $5(1.7 \%)$ & & \\
\hline SGLT-2 inhibitor & $3(1.0 \%)$ & & \\
\hline Meglitinides & $1(0.3 \%)$ & & \\
\hline Acarbose & $0(0 \%)$ & & \\
\hline
\end{tabular}

Table 1. Comparison of patient characteristics between diabetes and non-diabetes patients. ${ }^{1} \mathrm{FPS}$ missing values $=16(5.5 \%) .{ }^{2} \mathrm{HbA} 1 \mathrm{c}$ missing values $=143(49.5 \%) .{ }^{3}$ Asprin use missing values $=9$. Significant $\mathrm{P}$-values are bolded.

\section{Results}

A total of 5395 screening colonoscopy reports (January 1, 2012-December 31, 2015) were identified using the endoscopy reporting software at Stony Brook University Hospital (SBUH), a New York state funded academic medical center in Long Island, New York. Manual curation of the endoscopy reports was conducted with review of the linked EMRs (clinical notes, laboratory values and pathology reports) and led to the exclusion of patients that had undergone a previous screening colonoscopy, patients that reported rectal bleeding, patients with a positive fecal occult blood test, patients with a known hereditary CRC syndrome, or patients age $<45 \mathrm{y}$ and $\geq 76 \mathrm{y}$. From a total of 2984 initial screening colonoscopies performed on patients age $\geq 45 \mathrm{y}$ or $\leq 75$ years, an additional 119 initial screening colonoscopies were excluded from this analysis because they were incomplete exams and/or had a poor bowel preparation. 


\begin{tabular}{|l|l|l|l|c|}
\hline Variables & & $\begin{array}{l}\text { Diabetes } \\
\mathbf{n = 2 8 9}\end{array}$ & $\begin{array}{l}\text { Non-diabetes } \\
\mathbf{n = 2 5 7 6}\end{array}$ & P-value \\
\hline Adenoma & $\geq 1$ polyp & $121(41.9 \%)$ & $692(26.9 \%)$ & $<\mathbf{0 . 0 0 0 1}$ \\
\hline Location of adenoma & $\begin{array}{l}\text { Left-sided only } \\
\text { Right-sided only } \\
\text { Both }\end{array}$ & $\begin{array}{l}53(43.8 \%)^{\mathrm{a}} \\
46(38.0 \%) \\
22(18.2 \%)\end{array}$ & $\begin{array}{l}271(39.2 \%) \\
297(42.9 \%) \\
124(17.9 \%)\end{array}$ & 0.56 \\
\hline $\begin{array}{l}\text { Non-serrated adenoma vs. } \\
\text { Sessile serrated/Traditional } \\
\text { serrated adenomas }\end{array}$ & $\begin{array}{l}\text { Non-serrated adenomas } \\
\text { Sessile serrated/Traditional serrated } \\
\text { adenomas }\end{array}$ & $\begin{array}{l}116(95.9 \%)^{\mathrm{a}} \\
5 / 0(4.1 \%)\end{array}$ & $\begin{array}{l}655(94.7 \%) \\
36 / 1(5.3 \%)\end{array}$ & 0.66 \\
\hline Advanced adenoma & & $40(33.1 .0 \%)^{\mathrm{a}}$ & $205(29.6 \%)$ & 0.45 \\
\hline High risk adenoma & & $51(42.1 \%)^{\mathrm{a}}$ & $250(36.1 \%)$ & 0.22 \\
\hline Carcinoma & & $1(0.8 \%)^{\mathrm{a}}$ & $2(0.3 \%)$ & 0.37 \\
\hline Hyperplastic polyp only & & $31(10.7 \%)$ & $269(10.4 \%)$ & 0.92 \\
\hline
\end{tabular}

Table 2. Comparison of types and locations of polyps in diabetes and non-diabetes patients. ${ }^{\text {aPercentages of }}$ patients with only adenomas.

As shown in Table 1, 282 (9.8\%) of the patients had type 2 diabetes and 7 (2.4\%) had type 1 diabetes. Patients were predominantly White/European Ancestry (EA). Differences in patient characteristics between the patients with and without diabetes included median age, sex, race, BMI, smoking status, aspirin use, quality of colonoscopic prep and insurance status, but not Hispanic ethnicity or family history of CRC in a first degree relative.

Patients with diabetes had a median FPG level of $129 \pm 51 \mathrm{mg} / \mathrm{dl}$. HbAlc levels were documented within the SBUH EMR in only approximately half of the patients, possibly because many of the patients were followed by primary physicians or endocrinologists outside of the institution where results were not available. Of the recorded HbAlc levels, the median $\mathrm{HbAlc}$ was $7.2 \pm 1.5 \%$ ( $55 \mathrm{mmol} / \mathrm{mol})$. The number of patients with diabetes with $\mathrm{HbAlc}>9 \%(75 \mathrm{mmol} / \mathrm{mol})$ deemed a threshold value for poor glycemic control, was 17 (11.64\% of 146 patients with recorded $\mathrm{HbAlc})^{15}$. The number of patients with $\mathrm{HbAlc}<8 \%(64 \mathrm{mmol} / \mathrm{mol})$ moderate control, was 110 (75.34\% of the 146 patients with recorded HbAlc). The number of patients with $\mathrm{HbA1c}<7 \%(53 \mathrm{mmol} / \mathrm{mol})$ good control, was 65 (44.52\% of the 146 patients with recorded HbAlc). Although there was a significant correlation between pre-procedure FPG and $\mathrm{HbAlc}(\mathrm{p}=0.0001)$ in the 141 subjects with both values measured/available, HbAlc classification of poor glycemic control could not be well predicted by glucose level alone (AUC $=0.73$ with 95\% CI: 0.64-0.81).

The treatment of patients with diabetes is summarized in Table $1 ; 10.4 \%$ of patients were on no diabetes medications. Patients were often treated with more than one anti-diabetes medication. For example, of the $59(20.4 \%)$ patients with diabetes treated with insulin, 29 (10.03\%) were also on additional oral diabetes agents. Of the 190 (65.7\%) patients with diabetes treated with metformin, $82(28.37 \%)$ were on other oral agents and/or insulin. Of the $73(25.3 \%)$ patients with diabetes on a sulfonylurea, $58(20.07 \%)$ were on other oral agents (most commonly metformin) and/or insulin. Of the 38 (13.1\%) patients with diabetes treated with DPP4 inhibitors, 32 (11.07\%) were on other oral agents and/or insulin.

The colonoscopic outcomes with respect to the type and location of polyps are summarized in Table 2. Patients with diabetes had a significantly higher prevalence of adenomas and advanced adenomas than those without diabetes. However, the distribution of the polyps with respect to colon location or number of adenomas, did not differ significantly between the two groups.

Multivariable analysis, which took into consideration potential confounding factors associated with an increased risk of colonic neoplasia (see Table 3) suggests that type 2 diabetes was significantly associated with a higher $\operatorname{ADR}(\mathrm{OR}=1.49,95 \% \mathrm{CI}: 1.13-1.97, \mathrm{p}=0.0047)$. In addition, multivariable analysis identified older age, male sex, smoking and increased BMI was associated with a higher ADR. Type 2 diabetes was not significantly associated with AADR after taking into consideration multiple confounding variables $(\mathrm{OR}=1.28,95 \% \mathrm{CI}$ : $0.85-1.93, \mathrm{p}=0.24$, see Table 4 ). However older age, male sex, smoking and increased BMI were also significantly associated with an increased AADR. For patients with type 2 diabetes, patients who were not taking diabetes medications were more likely to have an adenoma than patients who were taking diabetes medication $(\mathrm{OR}=2.38$, $95 \%$ CI: $1.09-5.2, \mathrm{p}=0.03)$. No other variables were significantly associated with ADR or AADR among patients with type 2 diabetes.

\section{Discussion}

In designing this retrospective study, a great deal of effort was made to accurately record and thus control for multiple confounding covariables that have been previously associated with increased CRC risk, to address the effect of diabetes on colorectal adenoma-carcinoma progression. Because operators may designate colonoscopies as screening rather than diagnostic, despite presence of a positive fecal occult blood test or history of rectal bleeding, the linked EMRs were carefully reviewed to exclude these cases. This is because the ADR in patients with a positive fecal occult blood test is significantly higher and inclusion of these patients would likely skew the outcome we were using to measure colorectal adenoma-carcinoma progression ${ }^{16,17}$. Similarly, care was made to exclude surveillance colonoscopies by carefully reviewing all the pathology reports in the EMR to eliminate any surveillance colonoscopies labeled as screening colonoscopies, which could also potentially skew the ADR outcome ${ }^{18}$. Only initial screening colonoscopies were included, because repeat screening colonoscopies were performed with varying intervals ranging from 5-10 years which could also skew the probability of finding a neoplastic lesion. We 


\begin{tabular}{|c|c|c|c|c|}
\hline Variable & Levels & Odds ratio & $95 \% \mathrm{CI}$ & P-value \\
\hline Type 2 diabetes & Type 2 diabetes vs. non-diabetes & 1.49 & $1.13-1.97$ & 0.0047 \\
\hline $\mathrm{BMI} \mathrm{kg} / \mathrm{m}^{2}$ & Every 1 unit increase & 1.02 & $1-1.03$ & 0.027 \\
\hline Smoking & $\begin{array}{l}\text { Current vs. Never } \\
\text { Current vs. Quit }\end{array}$ & $\begin{array}{l}1.44 \\
1.22\end{array}$ & $\begin{array}{l}1.12-1.86 \\
0.92-1.61\end{array}$ & 0.012 \\
\hline Age (y) & Every 1 year increase & 1.05 & $1.03-1.06$ & $<0.0001$ \\
\hline Sex & Male vs Female & 1.96 & $1.64-2.34$ & $<0.0001$ \\
\hline \multirow{3}{*}{ Race } & Black/AA vs. White/EA & 0.79 & $0.55-1.16$ & \multirow{3}{*}{0.57} \\
\hline & Asian vs. White/EA & 1.12 & $0.68-1.85$ & \\
\hline & Other vs. White/EA & 0.86 & $0.52-1.43$ & \\
\hline Ethnicity & Hispanic vs. non-Hispanic & 0.9 & $0.62-1.32$ & 0.59 \\
\hline Family History of CRC & History vs. no history & 1.02 & $0.69-1.5$ & 0.94 \\
\hline Aspirin use & Yes vs No & 0.94 & $0.73-1.21$ & 0.63 \\
\hline \multirow{3}{*}{$\begin{array}{l}\text { Quality of colonoscopic } \\
\text { prep }\end{array}$} & Good vs. Excellent & 1.31 & $1.05-1.64$ & \multirow{3}{*}{0.054} \\
\hline & Fair vs. Excellent & 1 & $0.64-1.55$ & \\
\hline & Undocumented vs. Excellent & 1.01 & $0.65-1.56$ & \\
\hline Fellow Involvement & Yes vs. No & 1.08 & $0.86-1.36$ & 0.5 \\
\hline \multirow{3}{*}{ Insurance } & Commercial vs. Medicare & 1.21 & $0.89-1.65$ & \multirow{3}{*}{0.095} \\
\hline & Commercial vs. Medicaid & 0.84 & $0.66-1.07$ & \\
\hline & Commercial vs. Self-Pay & 0.6 & $0.33-1.08$ & \\
\hline
\end{tabular}

Table 3. Multivariable analysis of adenoma detection rate (ADR) on initial screening colonoscopy performed on patients with type 2 diabetes and non-diabetes patients. The estimated odds ratio and their $95 \%$ confidence intervals (CI) for the effect of each covariation on ADR were based on a multivariable generalized linear mixed model (GLMM) considering attending physician as a random effect. The p-values were based on type 3 analysis from the multivariable GLMM model. The p-values $<0.05$ are bolded.

\begin{tabular}{|c|c|c|c|c|}
\hline Variable & Levels & Odds ratio & $95 \% \mathrm{CI}$ & P-value \\
\hline Type 2 diabetes & Type 2 diabetes vs. non-diabetes & 1.28 & $0.85-1.93$ & 0.24 \\
\hline $\mathrm{BMI} \mathrm{kg/ \textrm {m } ^ { 2 }}$ & Every 1 unit increase & 1.03 & $1.01-1.05$ & 0.0096 \\
\hline \multirow{2}{*}{ Smoking } & Current vs. Never & 1.94 & $1.34-2.81$ & \multirow{2}{*}{0.0019} \\
\hline & Current vs. Quit & 1.62 & $1.09-2.42$ & \\
\hline Age (y) & Every 1 year increase & 1.05 & $1.03-1.08$ & $<0.0001$ \\
\hline Sex & Male vs Female & 2.4 & $1.79-3.22$ & $<0.0001$ \\
\hline \multirow{3}{*}{ Race } & Black/AA vs. White/EA & 0.83 & $0.47-1.5$ & \multirow{3}{*}{0.55} \\
\hline & Asian vs. White/EA & 0.45 & $0.14-1.47$ & \\
\hline & Other vs. White/EA & 0.89 & $0.36-2.18$ & \\
\hline Hispanic & Hispanic vs. non-Hispanic & 0.6 & $0.3-1.2$ & 0.15 \\
\hline Family History of CRC & History vs. no history & 1.16 & $0.64-2.13$ & 0.62 \\
\hline Aspirin use & Yes vs No & 0.74 & $0.49-1.11$ & 0.15 \\
\hline \multirow{3}{*}{ Quality of colonoscopic prep } & Good vs. Excellent & 1.32 & $0.92-1.9$ & \multirow{3}{*}{0.33} \\
\hline & Fair vs. Excellent & 0.98 & $0.49-1.97$ & \\
\hline & Undocumented vs. Excellent & 1.56 & $0.82-2.94$ & \\
\hline Fellow Involvement & Yes vs. No & 1.11 & $0.78-1.58$ & 0.58 \\
\hline \multirow{3}{*}{ Insurance } & Commercial vs. Medicare & 1.13 & $0.71-1.8$ & \multirow{3}{*}{0.24} \\
\hline & Commercial vs. Medicaid & 0.72 & $0.5-1.04$ & \\
\hline & Commercial vs. Self-Pay & 0.63 & $0.25-1.59$ & \\
\hline
\end{tabular}

Table 4. Multivariable analysis of advanced adenoma detection rate (AADR) on initial screening colonoscopy performed on type 2 diabetes and non-diabetes patients. The estimated odds ratio and their $95 \%$ confidence intervals (CI) for each covariate were based on a fixed multivariable generalized linear mixed (GLMM) model on ADR. The p-values were based on type 3 analysis from the multivariable GLMM model. The p-values $<0.05$ are bolded.

opted to study the entire cohort rather than selecting only certain reports using a case control design in order to avoid possible selection bias.

Since ADR is used as a quality metric, a major confounding variable was operator dependence. A review of Medicare data revealed that colonoscopies performed on Black/AA patients were more likely to be performed by operators with low polyp detection. Individual operator ADR have been closely monitored in the SBUH endoscopy suite, which participates in the American Society of Gastrointestinal Endoscopy (ASGE) Endoscopy Unit 
Recognition Program (EURP). The analyses were conducted with physicians clustered as a random variable to control for operator dependence.

The results suggest that type 2 diabetes is significantly associated with an increased risk of detecting at least one adenoma. We were not able to determine the effect of glycemic control in this study because of missing HbAlc values and because only a minority of patients were documented to have poor control. Onitillo et $\mathrm{al}^{19}$. reported that they detected no association between glycemic control and colorectal cancer risk and suggested that hyperinsulinemia rather than hyperglycemia was contributing to increased colorectal cancer risk. In this study, there was no significant effect of metformin use on $\mathrm{ADR}(\mathrm{p}=0.12)$ although we detected a higher ADR among patients with type 2 diabetes not taking anti-diabetes medications compared to those who were treated. In addition, we detected two potentially modifiable variables, increased BMI and smoking, as significantly associated with both increased ADR and AADR. These results support developing prospective observational studies to measure fasting insulin levels and $\mathrm{HbA1c}$ in all patients undergoing initial screening colonoscopy to determine whether insulin resistance and/or hyperinsulinemia contribute to increased risk of developing adenomas. Future research studies are needed to better understand colorectal carcinogenesis. One promising direction is molecular pathologic epidemiology (MPE) which can provide unique opportunities to examine the influence of diet, lifestyle, and environmental exposures on specific pathways of adenoma carcinoma progression ${ }^{20}$.

Received: 29 October 2019; Accepted: 13 March 2020;

Published online: 08 May 2020

\section{References}

1. Howlander, N. N. A. et al. SEER Cancer Statistics Review, 1975-2015. National Cancer Institute. Bethesda, MD, https://seer.cancer. gov/csr/1975_2015/.

2. Colussi, D. et al. Molecular pathways involved in colorectal cancer: implications for disease behavior and prevention. Int. J. Mol. Sci. 14, 16365-85 (2013).

3. Coleman, H. G. et al. Colorectal Cancer Risk Following Adenoma Removal: A Large Prospective Population-Based Cohort Study. Cancer Epidemiol. Biomarkers Prev. 24, 1373-80 (2015).

4. Siegel, R. L., Miller, K. D. \& Jemal, A. Cancer statistics, 2018. CA: A Cancer J. Clinicians. 68, 7-30, https://doi.org/10.3322/caac.21442 (2018).

5. Johnson, C. M. et al. Meta-analyses of Colorectal Cancer Risk Factors. Cancer causes control: CCC 24, 1207-1222 (2013).

6. Giovannucci, E. \& Willett, W. C. Dietary factors and risk of colon cancer. Ann. Med. 26, 443-52 (1994).

7. Larsson, S. C., Orsini, N. \& Wolk, A. Diabetes mellitus and risk of colorectal cancer: a meta-analysis. J. Natl Cancer Inst. 97, 1679-87 (2005).

8. Centers for Disease Control and Prevention. National Diabetes Statistics Report, 2017. Atlanta, GA: Centers for Disease Control and Prevention, US Department of Health and Human Services; (2017).

9. Dash, C. et al. Type 2 diabetes and the risk of colorectal adenomas: Black Women's Health Study. Am. J. Epidemiol. 179, 112-9 (2014).

10. Elwing, J. E. et al. Type 2 diabetes mellitus: the impact on colorectal adenoma risk in women. Am. J. Gastroenterol. 101, $1866-71$. (2006).

11. Eddi, R. et al. Association of type 2 diabetes and colon adenomas. J. Gastrointest. Cancer 43, 87-92 (2012).

12. Yu, F. et al. Type 2 diabetes mellitus and risk of colorectal adenoma: a meta-analysis of observational studies. BMC Cancer 16, 642 (2016).

13. Budzynska, K. et al. Diabetes Mellitus and Hyperglycemia control on the risk of colorectal adenomatous polyps: a retrospective cohort study. BMC Family Pract. 19, 145 (2018).

14. David, Y. et al. Confounders in Adenoma Detection at Initial Screening Colonoscopy: A Factor in the assessment of Racial Disparities as a Risk for Colon Cancer. J. Cancer Ther. 10(4), 269-289 (2019).

15. Shahraz, S. et al. Change in Testing, Awareness of Hemoglobin Alc Result, and Glycemic Control in US Adults, 2007-2014. JAMA. 318, 1825-1827 (2017).

16. Hassan, C., Repici, A. \& Rex, D. K. FITting ADR to colonoscopy indication. U Eur. Gastroenterol. J. 5, 149-152 (2017).

17. Kligman, E. et al. Adenoma Detection Rate in Asymptomatic Patients with Positive Fecal Immunochemical Tests. Dig. Dis. Sci. 63, 1167-1172 (2018).

18. Boroff, E. S. et al. Adenoma and Polyp Detection Rates in Colonoscopy according to Indication. Gastroenterol. Res. Pract. 2017, 7207595 (2017)

19. Onitilo, A. A. et al. Type 2 diabetes mellitus, glycemic control, and cancer risk. Eur. J. Cancer Prev. 23, 134-40 (2014).

20. Lochhead, P. et al. Progress and opportunities in molecular pathological epidemiology of colorectal premalignant lesions. Am. J. Gastroenterol. 109(8), 1205-1214 (2014).

\section{Acknowledgements}

We wish to thank Li Huang MD and Ayanna E. Lewis MD for their assistance in data collection. The authors wish to acknowledge the Biostatistics and Bioinformatics Shared Resource, the Stony Brook Cancer Center for expert assistance with statistical analysis. Guarantors: Joshua D. Miller MD, MPH, Lorenzo F. Ottaviano MD. TRO fusion grant (Miller, PI) P20 CA192994 (Li, PI), Simons Foundation 74038 (Li, PI).

\section{Author contributions}

Study concept and design: Joshua Miller, Ellen Li, Matthew Murray, Lorenzo Ottaviano. Data Collection: Jesse Frye, Brandon Lung, Lorenzo Ottaviano, Mathew Murray, Yiying Zhang, Ellen Li. Statistical analysis: Xueying $\mathrm{Li}$, Jie Yang. Interpretation of analysis results: Xueying Li, Jie Yang. Erin Taub, Lorenzo Ottaviano, Joshua Miller, Ellen Li. Drafting of Manuscript: Lorenzo Ottaviano, Joshua Miller, Ellen Li. Critical Review for Important Intellectual Content: Xueying Li, Jie Yang. Joshua Miller, Ellen Li, Jonathan M. Buscaglia, Juan Carlos Bucobo. Study Supervision: Joshua Miller, Ellen Li.

\section{Competing interests}

The authors declare no competing interests. 
Additional information

Correspondence and requests for materials should be addressed to J.D.M.

Reprints and permissions information is available at www.nature.com/reprints.

Publisher's note Springer Nature remains neutral with regard to jurisdictional claims in published maps and institutional affiliations.

(c) (i) Open Access This article is licensed under a Creative Commons Attribution 4.0 International License, which permits use, sharing, adaptation, distribution and reproduction in any medium or format, as long as you give appropriate credit to the original author(s) and the source, provide a link to the Creative Commons license, and indicate if changes were made. The images or other third party material in this article are included in the article's Creative Commons license, unless indicated otherwise in a credit line to the material. If material is not included in the article's Creative Commons license and your intended use is not permitted by statutory regulation or exceeds the permitted use, you will need to obtain permission directly from the copyright holder. To view a copy of this license, visit http://creativecommons.org/licenses/by/4.0/.

(C) The Author(s) 2020 